золотосодержащих продуктов содержащих железа и медь [Текст] / Л. С. Стрижко, И. Р. Бобоев // ВосточноЕвропейский журнал передовых технологий. - 2012. - Т. 6, № 6 (60). - С. 66-69. - Режим доступа: http://journals.uran.ua/eejet/article/view/5572/5013

3. Стрижко, Л. С. Исследование и разработка технологии извлечения золота из окисленных руд одного из крупнейших месторождений Таджикистана [Текст] / Л. С. Стрижко, Б. А. Бобохонов, И. Р. Бобоев // Цветные металлы. - 2012. - № 7. - С. 41-44.

4. Fang, Zh. Leach out gold and silver from sulfide concentrate copper with cyanide and ammonia solutions [Text] / Zh. Fang // Minerals Engineering. - 1992. - Vol. 2, Issue 1. P. 43-53.

5. Захаров, В. А. Золото: упорные руды [Текст] / В. А. Захаров, М. А. Меретуков. - М. : Руда и Металлы, 2013. $-452 \mathrm{c}$.

6. Стрижко, Л. С. Металлургия золота и серебра [Текст] : уч. пос. / Л. С. Стрижко. - М. : МИСиС, 2001. $336 \mathrm{c}$.

7. Бобохонов, Б. А. СП «Зарафшон»: технологии переработки золотосодержащих руд [Текст] / Б. А. Бобохонов, Б. Р. Рабиев, И. Р. Бобоев // Горный журнал. Специальный выпуск. - 2012. - С. 46-50.

\section{References}

1. Strizhko, L. S., Bobozoda, Sh., Boboev, B. R., Berge,r B. R. (2014). Izvlechenie zolota iz zolotomed'soderzhashchego syr'y. Tsvetnye metally, 6, 37-41.

2. Strizhko, L. S., Boboev, I. R. (2012). Method for extracting gold from gold-products containing iron and copper. Eastern-European Journal of Enterprise Technologies, 6/6(60), 66-69. Available at: http://journals.uran.ua/eejet/article/view/ $5572 / 5013$

3. Strizhko, L. S., Bobokhonov, B. A., Boboev, I. R. (2012). Issledovanie i razrabotka tekhnologii izvlecheniya zolota iz okislennykh rud odnogo iz krupneyshikh mestorozhdeniy Tadzhikistana. Tsvetnye metally, 7, 41-44.

4. Fang, Zh. (1992). Leach out gold and silver from sulfide concentrate copper with cyanide and ammonia solutions. Minerals Engineering, 2 (1), 43-53.

5. Zakharov, V. A., Meretukov, M. A. (2013). Zoloto: upornye rudy. Moscow: Ruda i Metally, 452.

6. Strizhko L.S. (2001). Metallurgiya zolota i serebra. Moscow: MISiS, 336.

7. Bobokhonov, B. A., Rabiev, B. R., Boboev, I. R. (2012). SP «Zarafshon»: tekhnologii pererabotki zolotosoderzhashchikh rud. Gornyy zhurnal. Spetsial'nyy vypusk, 46-50.

Дата надходження рукопису 10.11.2014

Бобоев Икромджон Рахмонович, кандидат технических наук, младший научный сотрудник, кафедра цветных металлов и золота, Национальный исследовательский технологический университет «Московский институт стали и сплавов», пр. Ленинский, 4, Москва, Россия, 119991

E-mail: bobev-i@mail.ru

Стрижко Леонид Семенович, доктор технических наук, профессор, кафедра цветных металлов и золота, Национальный исследовательский технологический университете «Московский институт стали и сплавов», пр. Ленинский, 4, Москва, Россия, 119991

E-mail: sls_2007.47@mail.ru

Эргашев Нурбек Улугбекович, кафедра цветных металлов и золота, Национальный Исследовательский Технологический Университет «МИСиС», пр. Ленинский, 4, г. Москва, Россия, 119049

Горбунов Евгений Павлович, аспирант, кафедра цветных металлов и золота, Национальный Исследовательский Технологический Университет «МИСиС», пр. Ленинский, 4, г. Москва, Россия, 119049

\title{
УДК 663.8
}

DOI: $10.15587 / 2313-8416.2014 .31498$

\section{ИССЛЕДОВАНИЕ ПОКАЗАТЕЛЕЙ КАЧЕСТВА БЕЗАЛКОГОЛЬНЫХ НАПИТКОВ}

\author{
(C) М. А. Гулеватая, С. И. Усатюк
}

Статья посвящена исследованию показателей идентификации безалкогольных напитков отечественного производителя в соответствии с требованиями нормативной документации. Было проведено идентификацию маркировки продукиии, органолептическую оценку безалкогольных напитков дескрипторно-профильным методом с построением профилограмм, определено массовую долю сухих веществ рефрактометрическим методом, а также кислотность методом потенциометрического титрования

Ключевые слова: показатели качества, безалкогольный напиток, нормативная документация, маркировка

The article is devoted to investigation of identification indicators of non-alcoholic beverages by domestic producers in accordance with the requirements of regulatory documents. The identification of product labeling and organoleptic evaluation of non-alcoholic beverages by descriptive and profile method with the construction of profilograms is made. Dry solids weight ratio by refractometric method and acidity by potentiometric titration are determined

Keywords: quality indicators, non-alcoholic beverages, regulatory documents, labeling 


\section{1. Введение}

Сегодня индустрия безалкогольных напитков развивается очень динамично, постоянно расширяется ассортимент за счет напитков, изготовленных из концентратов, настоев пряноароматического сырья, которые обладают не только приятными вкусовыми свойствами, но и положительно влияют на органы и системы организма при включении их в рацион питания.

Ассортимент безалкогольной продукции, как на мировом рынке, так и в Украине, расширяется, в основном, за счет использования новых, нетрадиционных видов сырья, а также различных пищевых добавок, которые улучшают их органолептические и физико-химические показатели, но не всегда ассоциированы с пользой для здоровья потребителей.

\section{2. Постановка проблемы}

Рынок безалкогольных напитков с каждым годом пополняется все большим количеством новых продуктов, но нередко производители вводят потребителей в заблуждение, используя химические добавки без указания этого на упаковке. Эти вещества могут быть не только опасны, но и нести серьезную угрозу для жизни и здоровья человека.

Поэтому актуальным является исследование показателей идентификации безалкогольных напитков в соответствии с требованиями нормативной документации $[1,2]$.

Целью научных исследований было установление соответствия безалкогольной продукции отечественного производства требованиям нормативной документации за органолептическими и физикохимическими показателями, а также маркировки. Для реализации поставленной цели следовало решить такие задачи:

- выбрать образцы безалкогольных напитков отечественного производителя, популярные среди населения;

- выбрать номенклатуру показателей идентификации для безалкогольных напитков;

- проверить соответствие маркировки исследуемых образцов требованиям Технического регламента относительно правил маркировки пищевых продуктов;

- исследовать образцы безалкогольных напитков за органолептическими и физико-химическими показателями;

- установить соответствие исследуемых образцов безалкогольных напитков за органолептическими и физико-химическими показателями требованиям законодательства Украины.

\section{3. Литературный обзор}

Идентификация товаров является важным процессом при оценке качества и установления их соответствия требованиям нормативной документации. Изучению особенностей товароведческой экспертизы вкусовых товаров посвящали свои работы много отечественных и зарубежных ученых: Притульская Н. В., Дубинина А. А., Коломиец Т. М.,
Чепурной И. П., Шепелев А. Ф. и другие [3].

Идентификация требует многосторонних исследований товароведами-экспертами, а также высококвалифицированными учеными-экспертами. Поскольку результаты идентификации того или иного изделия анализируются и на основе этого анализа делают соответствующие выводы, то такой процесс можно назвать «идентификационной экспертизой». Это объясняется еще и тем, что без проведения идентификационной экспертизы нельзя установить группу товара, его код по ТН ВЭД $[4,5]$.

Критерии идентификации - характеристики товаров, позволяющие отождествлять наименование представленного товара с наименованием, указанным на маркировке, в нормативных и товаросопроводительных документах.

В нормативных документах приведены три группы показателей, а именно органолептические, физико-химические и микробиологические.

Однако для целей идентификации пригодны лишь органолептические и физико-химические показатели, что характеризуют собственно потребительские свойства самого товара. Микробиологические показатели относятся к показателям безопасности продовольственных товаров, существенно находятся под влиянием внешних факторов и поэтому не могут считаться критериям идентификации.

Непригодные в качестве критериев идентификации и некоторые физико-химические показатели безопасности, которые опосредованно свидетельствуют о загрязнении сырья и пищевых продуктов. Это касается таких показателей, как содержание токсичных элементов, радионуклидов, нитратов.

Требованиями к показателям критериев идентификации являются:

- типичность для конкретного вида или однородной группы продукции;

- объективность и сопоставимость;

- возможность проверки;

- трудности фальсификации.

Критерии, по которым можно идентифицировать товар, закладываются на этапах производства и отражаются в требованиях к качеству, которые установлены стандартами. Однако наличие нормативных документов не гарантирует того, что во время производства, хранения и реализации товаров фактический уровень качества будет полностью соответствовать установленным требованиям. Поэтому на всех этапах жизненного цикла - от производства через формирование ассортимента в торговле до приобретения товара потребителем - проводится его идентификация $[1,6]$.

Очень остро в Украине стоит вопрос безопасности и качества безалкогольной продукции: на прилавках магазинов много фальсифицированных, низкокачественных, а иногда и опасных для здоровья человека напитков.

Производство и реализация фальсифицированных напитков рядом с целенаправленным введением потребителей в заблуждение относи- 
тельно их свойств и происхождения может наносить прямой ущерб здоровью населения и способствовать недобросовестной конкуренции на продовольственном рынке. Кроме того, все более актуальной становится проблема ложной или такой, что вводит потребителей в заблуждение, маркировки пищевых продуктов. Неправильные и необоснованные данные на этикетках продукции могут касаться потребительских свойств, пищевой ценности, то есть непосредственно сферы безопасности продукции и защиты прав потребителей [7].

\section{4. Материалы и методы исследований}

Для идентификационной экспертизы безалкогольных напитков отечественного производителя были отобраны образцы напитков ТМ «Оболонь»: «Живчик с яблочным соком», «Живчик негазированный», «Живчик Уник», «Ситро» и «Квас Богатырский».

Информацию, указанную на этикетках безалкогольных напитков, сравнивали с требованиями Технического регламента относительно правил маркировки пищевых продуктов [8].

Определение органолептических показателей проводили согласно ДСТУ 7099 [9], физико-химические показатели, а именно кислотность ДСТУ 7102 [10], содержание сухих веществ ДСТУ 4855 [11].

\section{5. Результаты и их обсуждение}

Первым этапом экспериментального исследования было установление соответствия маркировки напитков требованиям Технического регламента относительно правил маркировки пищевых продуктов.

Все пищевые продукты, которые реализуются на территории страны, должны иметь маркировку на государственном языке, а в случае необходимости дополнительно может быть приведена информация также на других языках, и содержать в доступной для восприятия потребителем форме информацию согласно законодательству Украины [8].

Анализ маркировки образцов проводили, сравнивая фактически присутствующую на упаковке напитков информацию с перечнем обязательной информации при маркировке товаров.

Установлено, что маркировка содержит не всю обязательную информацию. Ни на одном из образцов не было данных о количестве пищевых добавок, а также в тех образцах, где их не должно быть, не указано, что они изготовлены без пищевых добавок. Такая информация предоставляется с целью предотвращения введения в заблуждение потребителя.

В опытных образцах отсутствуют предостережения относительно употребления безалкогольного напитка некоторыми категориями населения (детьми), несмотря на то, что в соответствии с рекомендациями Министерства здравоохранения Украины есть ограничение к употреблению детьми до 7 лет напитков, содержащих красители, ароматизаторы, подсластители.
Внешний вид безалкогольных напитков в бутылках вместимостью не более $1000 \mathrm{~cm}^{3}$ определяли визуально на соответствие требованиям нормативной документации на готовую продукцию. Оценивали правильность наклеивания этикетки, наличие перекосов, деформаций, разрывов, чистоту бутылок. Прозрачность и наличие инородных включений в безалкогольных напитках определяли, просматривая закупоренные бутылки на свете, переворачивая их при этом. Цвет безалкогольных напитков определяли визуально в чистом сухом цилиндрическом стакане вместимостью $250 \mathrm{~cm}^{3}$. Оценивают оттенок и интенсивность окраски на соответствие требованиям нормативно-технической документации на готовую продукцию.

Органолептические показатели напитков, товарных сиропов, сухих напитков обусловлены особенностями используемого сырья, способом обработки и должны соответствовать требованиям, установленным для каждого напитка в рецептуре. Органолептическую оценку качества безалкогольных напитков осуществляют по 5-балльной системе по следующим показателям качества: прозрачность, цвет, внешний вид, вкус и аромат, насыщенность $\mathrm{CO}_{2}$.

С целью научного подхода к определению уровня качества и более детального исследования образцов напитков применим методы сенсорного анализа с использованием профилирования качества и дескрипторно-профильного метода.

\section{Дескрипторно-профильный}

метод заключается в том, что для сенсорного анализа используется профилирование продукта с применением балловой оценки. Вся методика сводится к следующему:

- выбираются дескрипторы, показатели качества продукта, которые наиболее существенно характеризуют его органолептические свойства (чаще всего это могут быть стандартизированы показатели качества);

- выбирается 5-балльная шкала, которая наиболее удобна для оценки дескрипторов;

- разрабатывается профиль каждого показателя с учетом ранжирования его качества;

- проводится оценивание опытных образцов с определением фактического профиля каждого показателя;

- с целью установления общего профиля продукта разрабатывается шкала уровня качества [12].

C учетом указанной методики была разработана 5-бальная система оценивания качества органолептических показателей (дескрипторов) и проведено профилирование показателей качества безалкогольных напитков. Были выбраны следующие дескрипторы: вкус, внешний вид и прозрачность, цвет, аромат и насыщенность $\mathrm{CO}_{2}$.

С целью наглядного восприятия результатов исследования построено профилограммы для сравнения напитков (рис. 1, 2).

По результатам проведенного органолептического оценивания напитков можно сделать вывод, что все образцы имеют хорошее качество. 
Лучшие показатели качества имеет «Живчик с яблочным соком» (наиболее весомое влияние имели такие показатели, как: внешний вид, вкус и цвет), а, по сравнению, худшую - «Оболонь Ситро».

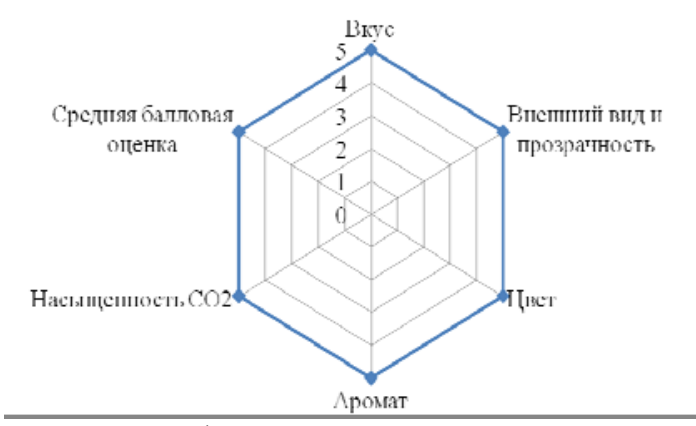

Рис. 1. Профилограмма напитка «Живчик с яблочным соком»

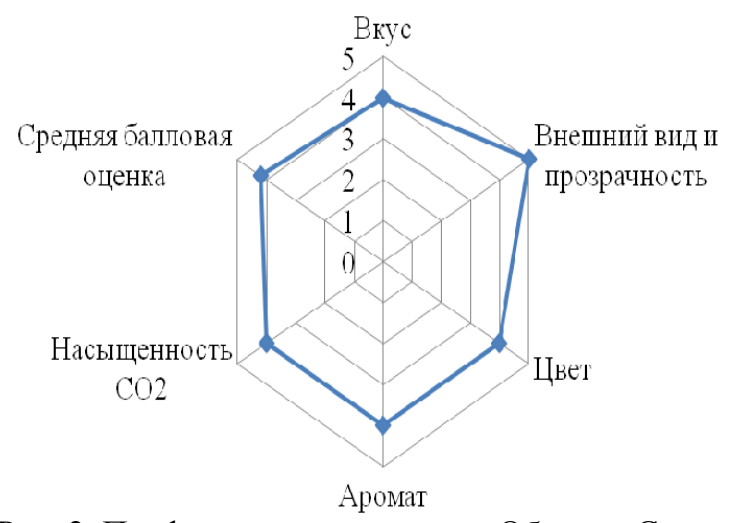

Рис. 2. Профилограмма напитка «Оболонь Ситро»
Определение массовой доли сухих веществ в безалкогольных напитках проводили рефрактометрическим методом, который основан на определении сухих веществ по шкале рефрактометра с обязательным удалением основного количества диоксида углерода из газированных напитков.

Результаты определения массовой доли сухих веществ в исследуемых образцах приведены на рис. 3.

Анализируя данные диаграммы, видим, что наибольшее количество сухих веществ содержат образцы «Живчик с яблочным соком» $(5,9 \%)$ и «Живчик негазированный» $(5,7 \%)$, а наименьшее «Живчик Уник» $(2,9 \%)$. Это объясняется низким содержанием яблочного сока (6 \%) и заменой сахара на фруктозу. В целом же, все результативные показатели находятся в пределах нормы.

Определение кислотности в исследуемых образцах проводили методом потенциометрического титрования с обязательным предварительным удалением основного количества диоксида углерода из газированных напитков.

Полученные значения активной кислотности (рис. 4) для напитков «Живчик с яблочным соком», «Живчик негазированный» и «Живчик Уник» объясняются добавлением лимонной и аскорбиновой кислот в сочетании с натуральным яблочным соком. Образцы «Оболонь Ситро» и «Квас Богатырский» имеют значительно более высокие значения $\mathrm{pH}-4,6$ и 5,5 соответственно, так как изготовлены без добавления сока.

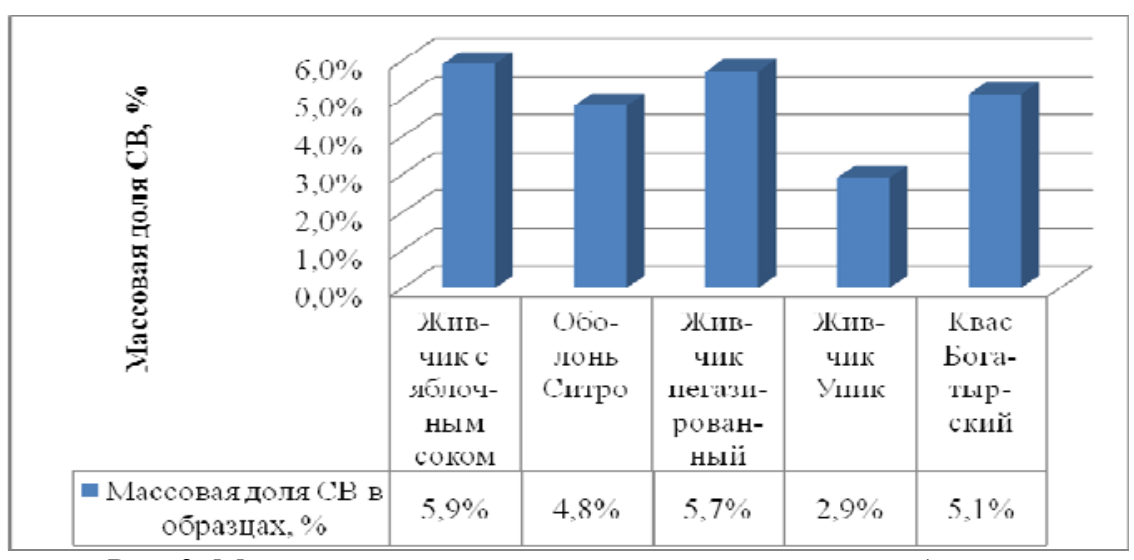

Рис. 3. Массовая доля сухих веществ в исследуемых образцах

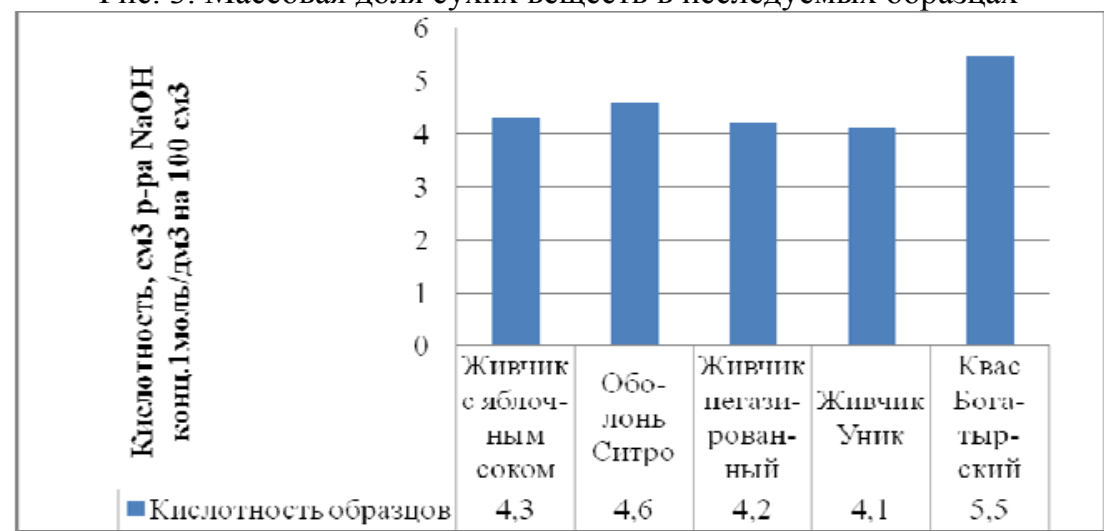

Рис. 4. Кислотность исследуемых образцов 


\section{6. Выводы}

В результате анализа идентификационных показателей установлено, что исследованные образцы напитков имеют неполную информацию в маркировке. Содержание сухих веществ в напитке «Живчик с яблочным соком» в 2 раза выше, чем в напитке «Живчик Уник». $\mathrm{pH}$ напитков с добавлением яблочного сока «Живчик с яблочным соком», «Живчик негазированный» и «Живчик Уник» находится в пределах 4,1...4,3, в то время как $\mathrm{pH}$ напитков «Оболонь Ситро» и «Квас Богатырский», которые изготовлены без добавления соков, составляет $4,6 \ldots 5,5$.

\section{Литература}

1. Бірта, Г. О. Товарознавство сировини, матеріалів та засобів виробництва: монографія [Текст] / Г. О. Бірта, Ю. Г. Бургу. - Полтава: ПУЕТ, 2012. - 275 с.

2. Вишневецька, О. В. Розвиток ринку продуктів харчування в Україні [Текст] / О. В. Вишневецька // Економіка АПК. - 2012. - № 7 (213). - С. 37-43.

3. Ткачук, В. В. Ідентифікаційна експертиза безалкогольного пива [Текст] / В. В. Ткачук, П. Є. Шейко // Економічний форум. - 2013. - № 3. - С. 145-148.

4. Дубініна, А. А. Методи визначення фальсифікації товарів [Текст]: підруч. / А. А. Дубініна, І. Ф. Овчиннікова, С. О. Дубініна та ін. - К.: ЦУЛ, 2010. - 272 с.

5. Смоляр, В. І. Харчова експертиза: підруч. [Текст] / В. І. Смоляр. - К.: Здоров'я, 2005. - 448 с.

6. Шепелев, А. Ф. Товароведение и экспертиза вкусовых и алкогольных товаров [Текст]: учебник / А. Ф. Шепелев, К. Р. Мхитарян. - Ростов на Дону: Март, 2001. $-208 \mathrm{c}$.

7. Евтушевская, О. А. Тенденции развития украинского рынка соков, нектаров, сокосодержащих напитков, морсов [Текст] / О. А. Евтушевская, С. И. Бабурина // Економіка харчової промисловості. - 2010. № 3. - С. 46-52.

8. Технічний регламент щодо правил маркування харчових продуктів [Текст] / Наказ Державного Комітету України 3 питань технічного регулювання та споживчої політики : від 28 жовтня 2010 p. Зареєстровано в Міністерстві юстиції України. - 2011. - N 183/18921. 2010ю - № 487. - 31с.

9. Продукція безалкогольної промисловості. Методи визначання органолептичних показників та об'єму продукції : ДСТУ 7099:2009 [Текст] / Введ. в дію 01.01.2011. - К.: Держстандарт України, 2009. - 12 с.

10. Продукція безалкогольної промисловості. Метод визначання кислотності : ДСТУ 7102:2009 [Текст] / Введ. в дію 01.01.2011]. - К.: Держстандарт України, 2009. -8 c.
11. Продукція безалкогольної промисловості. Методи визначення сухих речовин: ДСТУ 4855:2007 [Текст] / Введ. в дію 01.01.2009. - К.: Держстандарт України, 2007. - 19 с.

12. Домарецький, В. А. Технологія екстрактів, концентратів i напоїв із рослинної сировини: підруч. [Текст] / В. А. Домарецький, В. Л. Прибильський, М. Г. Михайлов. - Вінниця: Нова Книга, 2005. - 408 с.

\section{References}

1. Birta, H. O., Burhu, Y. H. (2012). Tovaroznavstvo syrovyny, materialiv ta zasobiv vyrobnycztva: monografiya. Poltava: PUET, 275.

2. Vyshneveczka, O. V. (2012). Rozvytok rynku produktiv xarchuvannya v Ukrayini. Ekonomika APK, 7 (213), $37-43$.

3. Tkachuk, V. V., Shejko, P. Ye. (2013). Identyfikacijna ekspertyza bezalkogolnogo pyva. Ekonomichnyj forum, 3, 145-148.

4. Dubinina, A. A., Ovchynnikova, I. F., Dubinina, S. O., Letuta, T. M. (2010). Metody vyznachennya falsyfikaciyi tovariv. Kyiv: CzUL, 272.

5. Smolyar, V. I. (2005). Xarchova ekspertyza. Kyiv: Zdorovya, 448

6. Shepelev, A. F., Mhitaryan, K. R. (2001). Tovarovedenie i ekspertiza vkusovyih i alkogolnyih tovarov. Rostov n/D: Mart, 208.

7. Evtushevskaya, O. A., Baburina, S. I. (2010). Tendentsii razvitiya ukrainskogo ryinka sokov, nektarov, sokosoderzhaschih napitkov, morsov. Ekonomika xarchovoyi promyslovosti, 3, 46-52.

8. Texnichnyj reglament shhodo pravyl markuvannya xarchovyx produktiv : nakaz Derzhavnogo Komitetu Ukrayiny $\mathrm{z}$ pytan texnichnogo regulyuvannya ta spozhyvchoyi polityky vid 28 zhovtnya 2010 (2010). Zareyestrovano v Ministerstvi yustyciyi Ukrayiny, 183/18921, 31.

9. DSTU 7099:2009 (2009). Produkciya bezalkogolnoyi promyslovosti. Metody vyznachannya organoleptychnyx pokaznykiv ta obyemu produkciyi (Nacionalnyj standart Ukrayiny). Kiev: Derzhstandart Ukrayiny, 12.

10. DSTU 7102:2009. (2009). Produkciya bezalkogol`noyi promy`slovosti. Metod vy`znachannya ky`slotnosti (Nacionalnyj standart Ukrayiny). Kyiv: Derzhstandart Ukrayiny, 8.

11. DSTU 4855:2007. (2007). Produkciya bezalkogolnoyi promyslovosti. Metody vyznachennya suxyx rechovyn (Nacionalnyj standart Ukrayiny). Kyiv: Derzhstandart Ukrayiny, 19.

12. Domareczkyj, V. A., Prybylskyj, V. L., Myxajlov, M. G. (2005). Texnologiya ekstraktiv, koncentrativ i napoyiv iz roslynnoyi syrovyny. Vinnycya: Nova Knyga, 408.

Рекомендовано до публікаиії д-р техн. наук Арсеньєв Л. Ю. Дата надходження рукопису 21.11.2014

Усатюк Светлана Ивановна, кандидат технических наук, доцент, кафедра экспертизы пищевых продуктов, Национальный университет пищевых технологий, ул. Владимирская, 68, г. Киев, Украина, 01601

E-mail: esmeraldo@ukr.net

Гулеватая Марина Анатольевна, аспирант, кафедра экспертизы пищевых продуктов, Национальный университет пищевых технологий, ул. Владимирская, 68, г. Киев, Украина, 01601

E-mail: FreeLife@ua.fm 